\title{
Eros e Psique - um vitral gnóstico de Almada Negreiros, de Cátia Mourão
}

Cristina Arena Forli ${ }^{1}$

José Sobral de Almada Negreiros, nascido em São Tomé, no ano de 1893, certamente foi uma das figuras mais marcantes da geração de Orpheu, revista portuguesa que teve como principais idealizadores Fernando Pessoa e Mário de Sá-Carneiro. Essa geração foi responsável pelo início do Modernismo em Portugal. Em consonância com o objetivo da revista, Almada tinha o intuito de realizar uma completa revolução artística e social e, para isso, era necessário romper com as formas estéticas reproduzidas até então no país. A fim de alcançar seu objetivo, o artista se vale de diferentes formas de expressão artística, trabalhando com a palavra, sob a forma da literatura, e também com a imagem, a partir das artes plásticas. Seus depoimentos ao público e produções artísticas revelam a postura rebelde e irreverente que tomou para si, buscando chocar a burguesia lusitana. Exemplo dessa postura é o depoimento em que afirma nenhuma arte lhe causar interesse, mas, sobretudo, o espetáculo, e este, para o autor, assume o significado de ver. O que Cátia Mourão faz em seu Eros e Psique - um vitral gnóstico de Almada Negreiros (editora Assembleia da República) é justamente ver uma leitura alternativa da obra do artista, de forma a evidenciar aspectos subjacentes à produção - a intervenção de José Manuel, quem a encomendou a Almada, e a relação entre a obra e a casa onde foi instalada.

O estudo de Cátia Mourão é motivado pela identificação dúbia do vitral, que passa a fazer parte das coleções da Assembleia da República em 2001. A indicação do tema Eros e Psique, feito pela proprietária para a venda, não condizia com a apresentação realizada em leilão, que identificava a peça como a representação da Queda de Ícaro. A pesquisadora, então, fica incumbida de realizar a análise pormenorizada do vitral a fim de identificá-lo de forma adequada. Para isso, Mourão divide seu livro em três partes: "Descrição do vitral", "Análise iconográfica" e "Uma iconografia em contexto: o vitral e a casa para onde foi concebido". Na primeira delas, realiza uma descrição minuciosa da peça de Almada a fim de facilitar a posterior análise. Considerando o fato de a obra não possuir reconhecimento público tão grande quanto os textos literários consagrados do artista, esta seção revela-se bastante oportuna. Composto por cinco partes de larguras diferentes, o vitral forma uma estrutura horizontal em que estão centralizadas duas figuras nuas, deitadas. Uma delas, a qual possui asas, dorme; a outra contempla o sono da primeira com o auxílio de uma lucerna, que ilumina o rosto desta.

A pesquisadora, já na segunda parte de seu livro, apresenta esboços ainda inéditos do vitral de Almada, os quais contribuem para a defesa de sua interpretação e possibilitam ao leitor o acompanhamento do processo de criação do artista. Ela chama a atenção para algumas interpretações já realizadas pela crítica que consideram a obra uma representação da queda de Ícaro, sendo Ícaro a figura com asas já caída e Dédalo a figura que observa, a fim de certificar-se da morte do filho. Contrapondo-se a essas interpretações, a autora defende, a partir dos estudos de Almada para a produção do vitral, que essas figuras representariam, na verdade, Eros e Psique.

1 Mestranda em Literaturas Portuguesa e Luso-africanas pela Universidade Federal do Rio Grande do Sul. 
Ao explicar o mito de Eros e Psique, Mourão vale-se da versão de Lúcio Apuleio, que identifica Eros com o Cupido romano e relaciona-o a Psique. Esta seria uma jovem cuja beleza desperta a adoração de todos os homens, os quais já não cultuam mais Vênus, deusa da beleza e mãe de Cupido. A deusa, a fim de vingar-se da jovem, pede ao filho que a faça se apaixonar por um homem feio. No entanto, Cupido apaixona-se por Psique, resultando na relação amorosa tão conhecida. A condição para ficarem juntos era a de que Psique jamais tentasse descobrir a identidade de seu amado. Tomada pela curiosidade, Psique não resiste e observa o rosto do amado enquanto este dorme. Entretanto, deixa cair uma gota de azeite da lamparina que acaba despertando-o. O deus foge por sentir-se traído. Vênus obriga Psique a cumprir diversos castigos. Um deles seria a busca de uma pequena caixa no mundo de Hades cujo conteúdo é a formosura de Prosérpina. Psique novamente não resiste à sua curiosidade e abre a caixa, a qual continha, na verdade, um sonífero que a faz cair em sono profundo. Cupido arrepende-se de ter fugido e então volta para acordar sua amada com o poder do amor.

A autora destaca a existência de diversas interpretações para o mito, as quais entendem Psique como a expressão da mente humana e Eros do amor e do mistério. Os estudos de Almada para a criação do vitral revelam as mudanças realizadas até se chegar ao estudo final, bastante semelhante à obra definitiva. Em relação àquele, esta tem como aspecto fundamental a alteração na fisionomia das personagens: a figura que dorme apresenta traços mais femininos e a que está acordada, mais masculinos. Mourão ressalta essa mudança na obra a fim de defender seu entendimento simbólico, gnóstico e hermético sobre ela, vendo-a como a representação da união entre os opostos por meio da equivalência e da identificação. A androginia das personagens, para a pesquisadora, possibilita duas leituras que podem ser equivalentes, as quais ela valida com a interpretação do poema hermético "Eros e Psique", de Fernando Pessoa, amigo de Almada e figura fundamental para o desenvolvimento do Modernismo em Portugal. Assim como o vitral, o final do poema também possui a metáfora da identificação: o Infante se reconhece na Princesa tal qual Eros se reconhece em Psique e Psique em Eros. Ao mesmo tempo em que permite o entendimento do mito como a metáfora do conhecimento, essa representação andrógina das personagens também possibilita a referência à Gnose unitária: Eros representa o agente que une e ordena os elementos do caos, tomado também como guia iniciático por filósofos herméticos, e também o amor que une os opostos; já Psique representa a alma e o espírito, que vivem no desconhecimento inicialmente. Ela seria, portanto, o Neófito iniciado por Eros nos processos gnósticos.

Cátia Mourão faz referência também a abordagens anteriores de Almada ao mito (a peça $\mathrm{O}$ mito de Psique e as produções plásticas), mostrando que elas, entretanto, não estabelecem o reconhecimento de uma personagem na outra. A união se dá, nesses casos, pelos paradoxos da relação conjugal e pelo confronto de opostos. $\mathrm{O}$ destaque dado às diferenças entre as figuras pelo artista indica, para a pesquisadora, a não filiação direta da ambiguidade do vitral a essas outras abordagens. Levando em consideração o fato de ter sido encomendado por José Manuel Ferrão, grande amigo de Almada cujas obras revelam sua relação com a temática do vitral, o orphista teria respeitado a ideia do amigo, não ressaltando então as diferenças entre as figuras. As obras de José Manuel também teriam inspirado outras produções de Almada, certificando, portanto, o nascimento do vitral devido ao profundo interesse do encomendante pelo seu tema.

Em "Uma iconografia em contexto: o vitral e a casa para onde foi concebido", é dado enfoque ao contexto da obra de Almada, tendo em vista que ela foi concebida para a 
biblioteca, local por excelência de reflexão, de José Manuel. O espaço constitui-se uma espécie de templo, com uma entrada exterior que possui um painel anexado à parede, também elaborado por Almada, em ângulo curvo e com motivos geométricos. A junção desses azulejos forma um pentagrama pitagórico, que comprova o estudo de Almada sobre a gênese do Conhecimento por meio da Geometria e do Número. A antecâmara e parte da biblioteca têm as paredes pintadas de preto, com linhas que indicam pentagramas, reiterando os temas do painel de azulejos e do tapete branco e preto da biblioteca, o que confirma a simbologia gnóstica da junção de opostos com a utilização da cor favorita de José Manuel, como Cátia mostra por meio de um poema do autor em que ele revela sua predileção. Os demais espaços da casa também dialogam com a biblioteca e da mesma forma apresentam símbolos gnósticos e da obra alquímica, os quais foram pensados pelos proprietários, José e Maria da Piedade, sua mãe, juntamente a Almada Negreiros e António Varela.

Eros e Psique - um vitral gnóstico de Almada Negreiros apresenta a produção do artista como uma representação imagética polissêmica, como a arte tem de ser, evidenciando uma metáfora do amor gnóstico unitário. A promoção das duas leituras pode fazer parecê-las diferentes, no entanto, elas se complementam, sobretudo, porque confluem para o dualismo inicial das personagens, promovendo a unificação no mito e na concepção gnóstica do mundo. Com base nesta concepção, Cátia Mourão expõe a interpretação do alcance de Psique ao conhecimento e à imortalidade, sendo esta conduzida pelas mãos de Eros. Para a pesquisadora, a maneira de representar o amor gnóstico vai ao encontro da ideia hermética das correspondências, visto que a união das personagens é subentendida pela figuração andrógina de ambas. Tendo em vista, desse modo, a abordagem da autora à coerência existente entre as interpretações do vitral, as obras da casa, a arquitetura e os demais elementos, fica absolutamente claro o sentido de unidade do espaço com as partes que o compõem.

O caráter inovador do livro de Mourão está, sobretudo, no enfoque dado à análise do espaço para o qual o vitral foi concebido, da relação entre esse espaço com os sentidos que a obra de arte produz e por considerar também os estudos de Almada Negreiros para chegar ao resultado final da produção. Se, como diz o orphista (1921, p. 18), o universo é "precisamente o resultado de haver quem [tem] olhos na própria cara", convido o leitor a acompanhar com seus olhos as reflexões da autora sobre o processo de criação do vitral, sobre o espaço de recebimento e, por fim, sobre a própria obra do artista. Assim, cada leitor pode contemplar à sua maneira os universos de Almada e de Mourão.

\section{Referências}

MOURÃO, Cátia. Eros e Psique - um vitral gnóstico de Almada Negreiros. Lisboa: Assembleia da República, s.d.

NEGREIROS, Almada. A invenção do dia claro. Lisboa: Olisipo, 1921. 